\title{
Intracellular Cystine Loading Causes Proximal Tubule Respiratory Dysfunction: Effect of Glycine
}

\author{
ABDULLAH SAKARCAN, REBECCA ARICHETA, AND MICHEL BAUM \\ Department of Pediatrics and Internal Medicine, University of Texas Southwestern Medical Center, \\ Dallas, Texas 75235-9063
}

\begin{abstract}
The present study examined proximal tubular respiration in control proximal tubules and proximal tubules loaded with cystine using $2 \mathrm{mmol} / \mathrm{L}$ cystine dimethyl ester. Basal oxygen consumption was significantly less in cystine-loaded tubules $(20.6 \pm 0.5$ versus $12.1 \pm 0.6$

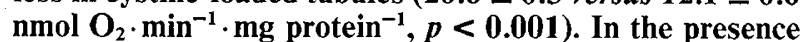
of $10^{-4} \mathrm{~mol} / \mathrm{L}$ ouabain, an inhibitor of the NaK ATPase, oxygen consumption was $10.2 \pm 0.7 \mathrm{nmol} \mathrm{O}_{2} \cdot \mathrm{min}^{-1} \cdot \mathrm{mg}$ protein $^{-1}$ in control tubules and $11.4 \pm 1.0 \mathrm{nmol} \mathrm{O} \cdot \mathrm{min}^{-1}$. mg protein ${ }^{-1}$ in cystine-loaded tubules. Thus, proximal tubular intracellular cystine loading specifically inhibits oxygen metabolism directed toward transport. Compared with control proximal tubules, cystine-loaded proximal tubules also had a lower rate of $\mathrm{O}_{2}$ consumption when the cells were permeabilized to sodium with nystatin and when mitochondrial respiration was uncoupled. Glycine, an amino acid that is cytoprotective to hypoxic proximal tubule injury, ameliorated the repiratory dysfunction observed in cystine-loaded tubules. (Pediatr Res 32: 710$713,1992)$
\end{abstract}

\section{Abbreviations}

NaK ATPase, sodium-potassium ATPase CCCP, p-chloromethyoxyphenylhydrazone CDME, cystine dimethyl ester

Cystinosis is an autosomal recessive disease characterized by high intracellular concentrations of the amino acid cystine (1$3)$. Cystine accumulates predominantly in lysosomes where a defect in cystine transport has been demonstrated (2-6). Cystine accumulation leads to dysfunction of several organs, including the kidney, where it is the most common inherited cause for the Fanconi syndrome in children (1). There is no animal model for the Fanconi syndrome of cystinosis. However, cells can be loaded with high concentrations of intracellular cystine using CDME (7, 8). CDME diffuses across cell membranes where intracellular esterases liberate the relatively impermeable cystine in high concentrations. Foreman et al. (9) have demonstrated that proximal tubules can be loaded with cystine using CDME to levels comparable to that in kidneys of patients with cystinosis.

We have recently demonstrated that intracellular cystine loading using CDME produces a decrease in volume absorption, transepithelial potential difference, glucose, and bicarbonate transport in proximal convoluted tubules perfused in vitro (10).

Received June 10, 1992; accepted August 7, 1992.

Correspondence and reprint requests: Michel Baum, M.D., Department of Pediatrics, University of Texas Southwestern Medical Center, 5323 Harry Hines Blvd., Dallas, TX 75235-9063.

Supported by an American Heart Association grant (890664).
There was no change in the permeability of proximal convoluted tubules to either mannitol or bicarbonate, indicating that the decrease in transport was due to an inhibition in active transport (10). Although intracellular cystine loading in proximal convoluted tubules did not affect $V_{\max }$ of NaK ATPase activity, it produced a profound decrease in intracellular ATP concentration (11). The purpose of the present study was to further characterize the metabolic defect in cystine-loaded proximal tubules and to examine if glycine, an amino acid that is cytoprotective to hypoxic proximal tubule injury, ameliorates the defect in proximal tubule respiration in cystine-loaded tubules.

\section{MATERIALS AND METHODS}

Rabbit proximal tubule suspensions were prepared using a method similar to that described by Weinberg et al. $(12,13)$. Briefly, kidneys were removed immediately after the rabbits were killed and placed in an ultrafiltrate-like solution at $4^{\circ} \mathrm{C}$ containing (in mmol/L) $115 \mathrm{NaCl}, 2.1 \mathrm{KCl}, 25 \mathrm{NaHCO}_{3}, 1.2 \mathrm{MgCl}_{2}, 1.2$ $\mathrm{MgSO}_{4}, 1.2 \mathrm{CaCl}_{2}$, and $2.4 \mathrm{KH}_{2} \mathrm{PO}_{4}$. This and other solutions were initially bubbled at $37^{\circ} \mathrm{C}$ with $95 \% \mathrm{O}_{2} / 5 \% \mathrm{CO}_{2}$.

The renal cortex was then minced on an ice-cold glass Petri dish using a razor blade. The tissue was placed in a previously silicone-coated flask (Sigma Coat, Sigma Chemical Co., St. Louis, $\mathrm{MO}$ ) with $24 \mathrm{~mL}$ of buffer containing (in mmol/L) $115 \mathrm{NaCl}$ $3.3 \mathrm{KCl}, 25 \mathrm{NaHCO}_{3}, 1.2 \mathrm{MgCl}_{2}, 1.2 \mathrm{MgSO}_{4}, 2.4 \mathrm{CaCl}_{2}, 25$ mannitol, 5 glucose, $4 \mathrm{Na}$ lactate, 1 alanine, $1 \mathrm{Na}$ butyrate, and $1.2 \mathrm{KH}_{2} \mathrm{PO}_{4}$. The solution also contained $2.5 \mathrm{mg} / \mathrm{mL}$ albumin (Sigma, Fraction V) and $1 \mathrm{mg} / \mathrm{mL}$ collagenase (Boehringer, Mannheim, Indianapolis, IN). The solution was gassed with $95 \%$ $\mathrm{O}_{2} / 5 \% \mathrm{CO}_{2}$ at $37^{\circ} \mathrm{C}$, and the tissue was then incubated in a sealed container at $37^{\circ} \mathrm{C}$ for $35 \mathrm{~min}$ in a shaker bath. After incubation, $75 \mathrm{~mL}$ of cold ultrafiltrate-like solution $\left(4^{\circ} \mathrm{C}\right)$ was added to stop the collagenase activity, and the suspension was filtered through four layers of gauze. The preparation was centrifuged at $800 \mathrm{rpm}$ for $2 \mathrm{~min}$ at $4^{\circ} \mathrm{C}$ to separate the tubules and glomeruli from the debris. The pellet was washed two more times with $50 \mathrm{~mL}$ of the ultrafiltrate-like solution and finally in $20 \mathrm{~mL}$ of an ultrafiltrate-like solution containing $5 \mathrm{~g} / \mathrm{dL}$ BSA (all at $\left.4^{\circ} \mathrm{C}\right)$.

The pellet was then resuspended in a $50 \%$ Percoll solution (Pharmacia, Piscataway, NJ) containing (in mmol/L) $100 \mathrm{NaCl}$, $26 \mathrm{NaHCO}_{3}, 3.4 \mathrm{KCl}, 1.2 \mathrm{KH}_{2} \mathrm{PO}_{4}, 1.2 \mathrm{MgSO}_{4}$, and $2.6 \mathrm{CaCl}_{2}$. The preparation was centrifuged at $13000 \mathrm{rpm}$ at $4^{\circ} \mathrm{C}$ for 30 min, which separated the denser proximal tubules from distal tubules and glomeruli. The proximal tubules were washed three times with an ultrafiltrate-like solution. The tubules were then resuspended in an ultrafiltrate-like solution that contained (in $\mathrm{mmol} / \mathrm{L}$ ) $4 \mathrm{Na}$ lactate, $10 \mathrm{Na}$ butyrate, 1 alanine, 5 glucose, and $0.6 \%$ dextran to yield a tubule suspension with a concentration of 5-6 mg protein $/ \mathrm{mL}$. (Less $\mathrm{NaCl}$ was added to this solution to maintain an osmolality of $290 \mathrm{mosmol} / \mathrm{kg}$ water.) The protein 
concentration was measured using the Lowry method with BSA as the standard (14). The tubule suspension was kept at $4^{\circ} \mathrm{C}$.

$\mathrm{O}_{2}$ consumption studies were performed in a 3-mL chamber using a Clark oxygen electrode (Yellow Springs Instrument Co., Yellow Springs, OH). The tubule suspension was first warmed to $37^{\circ} \mathrm{C}$, stirred, and gassed with $95 \% \mathrm{O}_{2}$ and $5 \% \mathrm{CO}_{2}$ for 10 min. In studies in which the effect of proximal tubular cystine loading was measured, $2 \mathrm{mmol} / \mathrm{L} \mathrm{CDME} \mathrm{(Sigma)} \mathrm{was} \mathrm{added} \mathrm{to}$ the tubule preparation at the time of incubation. The chamber was then sealed and $\mathrm{O}_{2}$ consumption was measured in $\mathrm{nmol} \mathrm{O}_{2}$. $\mathrm{min}^{-1} \cdot \mathrm{mg}$ protein ${ }^{-1}$. After the basal $\mathrm{O}_{2}$ consumption rate was measured, either nystatin $(200 \mu \mathrm{g} / \mathrm{mg}$ protein $)$, ouabain $\left(10^{-4}\right.$ $\mathrm{mmol} / \mathrm{L}$ ), or $15 \mu \mathrm{mol} / \mathrm{L}$ CCCP were added to the proximal tubule suspension, and the rate of $\mathrm{O}_{2}$ consumption was again measured. Nystatin permeabilizes the proximal tubule membranes to $\mathrm{Na}$ and increases the intracellular $\mathrm{Na}$ concentration. This allows determination of the maximal rate of coupled respiration. Ouabain inhibits the NaK ATPase, allowing determination of $\mathrm{O}_{2}$ consumption not used for transport. CCCP is a mitochondrial uncoupler and provides a measure of the maximal rate of tubular respiration.

The next series of experiments was designed to examine if glycine was cytoprotective to cystine-loaded proximal tubules. In these studies, the purified proximal tubules were resuspended in a solution containing either $5 \mathrm{mmol} / \mathrm{L}$ glycine, or $2.5 \mathrm{mmol} / \mathrm{L}$ $\mathrm{NaCl}$. $\mathrm{NaCl}$ was added as a control to keep the osmolality constant. $\mathrm{O}_{2}$ consumption studies were then performed in cystine-loaded tubules as described above. In addition, studies were performed to examine if glycine had an effect on proximal tubule respiration in the absence of cystine loading.

Data are expressed as mean \pm SEM. Statistical analysis was performed using the unpaired $t$ test and analysis of variance.

\section{RESULTS}

The results of $\mathrm{O}_{2}$ consumption studies in control and cystineloaded proximal tubules are shown in Table 1 and Figure 1. Basal $\mathrm{O}_{2}$ consumption in control proximal tubules was $20.6 \pm$ $0.5 \mathrm{nmol} \mathrm{O}_{2} \cdot \mathrm{min}^{-1} \cdot \mathrm{mg}$ protein ${ }^{-1}$. This value comprises total cellular respiration used for transport and nontransport functions. To determine the component of cellular respiration used for nontransport functions (i.e., non-NaK ATPase respiration) $10^{-4} \mathrm{~mol} / \mathrm{L}$ ouabain was added to the tubular suspension. The non-NaK ATPase respiration was $10.2 \pm 0.7 \mathrm{nmol} \mathrm{O}_{2} \cdot \mathrm{min}^{-1}$. $\mathrm{mg}$ protein $^{-1}$, which was significantly less than the basal $\mathrm{O}_{2}$ consumption $(p<0.001) . \mathrm{O}_{2}$ consumption directed to $\mathrm{NaK}$ ATPase or transport activity was $10.4 \mathrm{nmol} \mathrm{O} \mathrm{O}_{2} \cdot \mathrm{min}^{-1} \cdot \mathrm{mg}$ protein $^{-1}$, the difference between these values. Nystatin permeabilizes proximal tubule membranes to $\mathrm{Na}$ and maximizes $\mathrm{NaK}$ ATPase activity, allowing measure of the maximal NaK ATPase activity (the difference between the nystatin- and ouabain-treated $\mathrm{O}_{2}$ consumption rates). Nystatin increased $\mathrm{O}_{2}$ consumption over basal activity to $30.0 \pm 1.7 \mathrm{nmol} \mathrm{O}_{2} \cdot \mathrm{min}^{-1} \cdot \mathrm{mg}$ protein $^{-1}(p<$ 0.001 ). The maximal $\mathrm{NaK}$ ATPase activity was $19.8 \mathrm{nmol} \mathrm{O}_{2}$.

Table 1. Proximal tubular respiration*

\begin{tabular}{lcccc}
\hline & Basal & Ouabain & Nystatin & CCCP \\
\hline Control & $20.6 \pm 0.5$ & $10.2 \pm 0.7 \dagger$ & $30.0 \pm 1.7 \dagger$ & $64.0 \pm 3.3 \dagger$ \\
& $(129)$ & $(n=11)$ & $(n=18)$ & $(n=27)$ \\
$2 \mathrm{mM} \mathrm{CDME}$ & $12.1 \pm 0.6$ & $11.4 \pm 1.0$ & $17.6 \pm 1.3 \dagger \ddagger$ & $24.3 \pm 4.7 \dagger \ddagger$ \\
& $(n=88)$ & $(n=18)$ & $(n=57)$ & $(n=11)$ \\
$2 \mathrm{mM} \mathrm{CDME}$, & $16.5 \pm 1.8 \S \|$ & $11.4 \pm 1.5$ & $21.9 \pm 2.2 \S$ & $36.9 \pm 6.3 \dagger \ddagger$ \\
$\begin{array}{l}5 \mathrm{mM} \text { gly- } \\
\text { cine }\end{array}$ & $(n=43)$ & $(n=16)$ & $(n=14)$ & $(n=13)$ \\
\hline
\end{tabular}

* Values expressed as $\mathrm{nmol} \mathrm{O}_{2} \cdot \mathrm{min}^{-1} \cdot \mathrm{mg}$ protein ${ }^{-1}$.

$\dagger$ Different from basal of same group, $p<0.001$.

$\ddagger$ Different from comparably treated control, $p<0.001$.

$\S$ Different from comparably treated control, $p<0.01$.

|| Different from $2 \mathrm{mM}$ CDME, $p=0.01$.

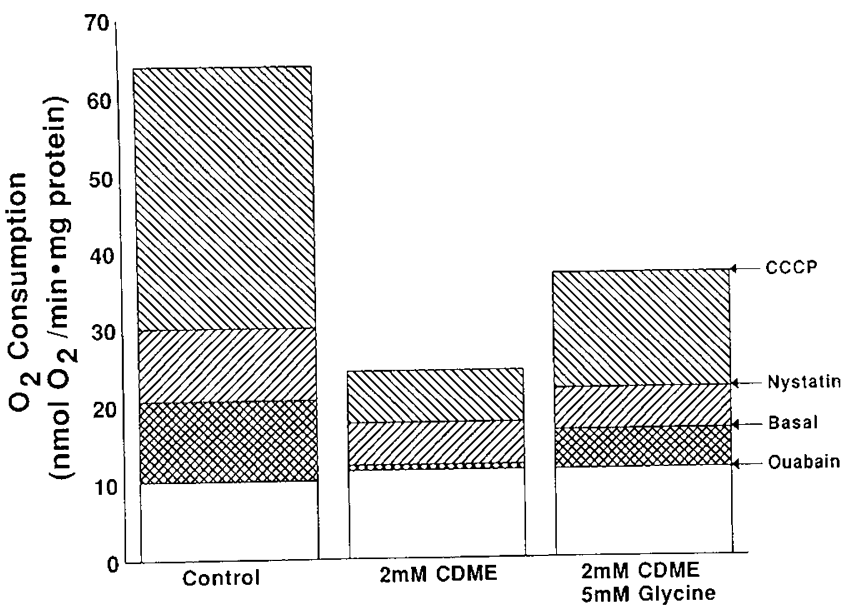

Fig. 1. $\mathrm{O}_{2}$ consumption in control tubules, cystine-loaded tubules, and cystine-loaded tubules in the presence of glycine. $\square, O_{2}$ consumption in the presence of ouabain; 睎, difference in $\mathrm{O}_{2}$ consumption between basal and ouabain-treated tubules; $\mathbb{2}$, difference in $\mathrm{O}_{2}$ consumption between nystatin-treated tubules and basal $\mathrm{O}_{2}$ consumption; and $\mathbb{\mathbb { N }}$, difference in $\mathrm{O}_{2}$ consumption between CCCP- and nystatin-treated tubules. $\mathrm{O}_{2}$ consumption used for transport ( $\mathrm{NaK}$ ATPase activity) is the difference between the basal and ouabain values. The difference in the nystatin value and that in the presence of ouabain is the maximal $\mathrm{NaK}$ ATPase activity. Uncoupled respiration was measured in the presence of CCCP.

$\min ^{-1} \cdot \mathrm{mg}$ protein ${ }^{-1}$. Uncoupled mitochondrial respiration was measured using $\mathrm{CCCP}$, which provides a measure of maximal $\mathrm{O}_{2}$ consumption. $\mathrm{O}_{2}$ consumption was $64.0 \pm 3.3$ in control tubules, which was higher than basal $\mathrm{O}_{2}$ consumption $(p<$ $0.001)$.

Cystine-loaded tubules had a basal $\mathrm{O}_{2}$ consumption of $12.1 \pm$ $0.6 \mathrm{nmol} \mathrm{O}_{2} \cdot \mathrm{min}^{-1} \cdot \mathrm{mg}$ protein ${ }^{-1}$, which was significantly less than the basal rate of control tubules $(p<0.001)$. In cystineloaded tubules, $\mathrm{O}_{2}$ consumption was $11.4 \pm 1.0 \mathrm{nmol} \mathrm{O} \cdot \mathrm{min}^{-1}$. mg protein ${ }^{-1}$ when $10^{-4} \mathrm{~mol} / \mathrm{L}$ ouabain was added to the tubule suspension. Thus, the non-NaK ATPase respiration was not different in control and cystine-loaded tubules. The $\mathrm{O}_{2}$ consumption directed to NaK ATPase activity was only $0.7 \mathrm{nmol}$ $\mathrm{O}_{2} \cdot \mathrm{min}^{-1} \cdot \mathrm{mg}$ protein ${ }^{-1}$. Thus, the difference in basal $\mathrm{O}_{2}$ activity between control and cystine-loaded tubules was entirely due to a decrease in transport-directed $\mathrm{O}_{2}$ consumption. In spite of the low $\mathrm{O}_{2}$ consumption used for $\mathrm{NaK}$ ATPase activity, nystatin did increase $\mathrm{O}_{2}$ consumption in cystine-loaded tubules to $17.6 \pm 1.3$ nmol $\mathrm{O}_{2} \cdot \min ^{-1} \cdot \mathrm{mg}$ protein ${ }^{-1}$. This value was significantly greater than basal $\mathrm{O}_{2}$ consumption, but less than that measured in control tubules in the presence of nystatin $(p<0.001)$. The maximal NaK ATPase activity was $6.2 \mathrm{nmol} \mathrm{O}_{2} \cdot \mathrm{min}^{-1} \cdot \mathrm{mg}$ protein $^{-1}$ in cystine-loaded tubules, compared with 19.8 in control tubules. Cystine-loaded tubules treated with CCCP had an $\mathrm{O}_{2}$ consumption of $24.3 \pm 4.7 \mathrm{nmol} \mathrm{O} \mathrm{O}_{2} \cdot \mathrm{min}^{-1} \cdot \mathrm{mg}$ protein ${ }^{-1}$, which was greater than the basal rate of $\mathrm{O}_{2}$ consumption, but significantly less than control tubules treated with CCCP $(p<$ $0.001)$.

Glycine has been shown to be cytoprotective to hypoxic injury in proximal tubules $(13,14)$. Inasmuch as an underlying defect in both models is a decrease in cellular ATP $(12,13,15)$ and the effect of ischemia on the above proximal tubular metabolic profile was similar to our present results in cystine-loaded tubules (16), the effect of $5 \mathrm{mmol} / \mathrm{L}$ glycine on cystine-loaded tubules was examined. In these studies, glycine was added when the proximal tubules were resuspended. In control tubules, 2.5 $\mathrm{mmol} / \mathrm{L} \mathrm{NaCl}$ was added to maintain a constant osmolarity. Glycine had no effect on basal respiration when added to control tubules $\left(n=29,20.0 \pm 1.1 \mathrm{nmol} \mathrm{O}_{2} \cdot \mathrm{min}^{-1} \cdot \mathrm{mg}\right.$ protein $\left.{ }^{-1}\right)$. The effect of glycine on respiration in cystine-loaded tubules is shown 
in Table 1 and Figure 1. Basal $\mathrm{O}_{2}$ consumption in cystine-loaded tubules incubated with $5 \mathrm{mmol} / \mathrm{L}$ glycine was $16.5 \pm 1.8 \mathrm{nmol}$

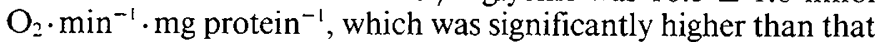
of cystine-loaded tubules incubated without glycine. There was no difference in $\mathrm{O}_{2}$ consumption in cystine-loaded tubules in the presence or absence of glycine after addition of either ouabain or CCCP. Cystine-loaded tubules incubated with nystatin had an $\mathrm{O}_{2}$ consumption of $21.9 \pm 2.2$ in the presence of glycine. Although this was not significantly different than the $17.6 \pm 1.3$ in all of our cystine-loaded tubules incubated with nystatin without glycine, control and cystine-loaded tubules were always run during each protocol to ensure the consistency of our preparation. The cystine-loaded, nystatin-treated tubules (containing 2.5 $\mathrm{mM} \mathrm{NaCl}$ ) run at the time of the glycine experiments had an $\mathrm{O}_{2}$ consumption of $14.6 \pm 2.5(n=11)$, which was lower than the cystine-loaded tubules treated with nystatin in the presence of glycine $(p<0.05)$. Thus, glycine partially ameliorated the basal and nystatin-stimulated $\mathrm{O}_{2}$ consumption in cystine-loaded tubules.

\section{DISCUSSION}

This study examined the effect of intracellular cystine loading on proximal tubule $\mathrm{O}_{2}$ consumption. Although cystine-loaded tubules had a lower rate of basal $\mathrm{O}_{2}$ consumption, there was no difference in $\mathrm{O}_{2}$ consumption when $\mathrm{NaK}$ ATPase activity was inhibited with ouabain. Intracellular cystine loading also decreased $\mathrm{O}_{2}$ consumption in the presence of nystatin and CCCP. Glycine partially ameliorated the decrease in basal and nystatinstimulated $\mathrm{O}_{2}$ consumption in cystine-loaded tubules.

The generalized proximal tubular defect in the Fanconi syndrome of cystinosis could potentially be due to a number of mechanisms. The proximal tubule reabsorbs most of the filtered bicarbonate, phosphate, amino acids, and glucose. The Fanconi syndrome could be due to a generalized decrease in active transport, or it could result from an increase in the permeability of the proximal tubule to these solutes, allowing greater diffusion from the blood into the tubular lumen. Potential mechanisms that could cause a generalized inhibition of active transport include a direct inhibition of the NaK ATPase on the basolateral membrane, a decrease in ATP production, or a generalized inhibition of the transports on the apical or basolateral membrane responsible for solute transport. These mechanisms have been examined using cystine-loaded tubules $(9-11,17)$. We have previously shown that the permeability of the proximal convoluted tubule to bicarbonate and mannitol is not affected by cystine loading consistent with an inhibition in active transport (10). Foreman et al. (17) found that the rate of proline uptake into brush border membrane vesicles obtained from cystineloaded tubules was not different than that in control tubules. Thus, cystine loading does not directly affect the transporters on the apical membrane. We have previously demonstrated that cellular cystine loading did not affect the $V_{\max }$ of NaK ATPase activity (11). Intracellular cystine loading, however, produced a substantial fall in intracellular ATP concentration (11). The results of the present study, which demonstrated that cellular cystine loading inhibits the rate of $\mathrm{O}_{2}$ consumption, are consistent with these previous results.

The approach used in the present study to examine the metabolic defect in cystine-loaded tubules has been previously used in the study of ischemic acute renal failure (16). In this study, rats had an ischemic insult to their kidney followed by various periods of reperfusion. There was a decrease in intracellular ATP concentration after the ischemic injury, but $\mathrm{V}_{\max } \mathrm{NaK}$ ATPase activity was not affected. In $\mathrm{O}_{2}$ consumption studies, proximal tubules harvested after the ischemic insult and 15 min of reperfusion had a lower rate of basal, nystatin-stimulated, and mitochondrial uncoupled $\mathrm{O}_{2}$ consumption compared with control proximal tubules. $\mathrm{O}_{2}$ consumption was the same in control and ischemic tubules in the presence of ouabain.
The present study demonstrates that $50 \%$ of $\mathrm{O}_{2}$ consumption in proximal tubules is used for NaK ATPase-dependent transport and the remainder for other cellular functions. As with ischemic injury, cystine loading almost totally and selectively inhibited $\mathrm{O}_{2}$ consumption directed to transport. The preservation of nontransport $\mathrm{O}_{2}$ consumption likely allows the proximal tubule cell to maintain essential cellular functions for survival and cell reparation. These data suggest that the proximal tubule cell is able to inhibit transport by inhibiting apical solute entry, the NaK ATPase activity, or the ATP pool directed for transport. The fact that nystatin resulted in a substantial, although brief, increase in cellular respiration suggests that the entry of solutes across the apical membrane could be inhibited when the intracellular ATP concentration falls.

The proximal tubular injury due to cystine loading shares many similarities with the proximal tubule injury due to hypoxia and ischemia $(13,16,18)$. Glycine has been shown to be cytoprotective against hypoxic injury to proximal tubules in suspension $(13,15)$. The cytoprotective effect of glycine is only apparent when glycine is present at the time of injury, but not when removed from the media before injury or when added after the tubules have been exposed to hypoxia (13). The mechanism of the cytoprotective effect of glycine is unknown. It does not act by increasing glutathione or ATP concentrations or via an action against reactive $\mathrm{O}_{2}$ metabolites $(13,15)$. Glycine had no effect on basal $\mathrm{O}_{2}$ consumption or ATP levels in control tubules (13). In the present study, glycine did not affect $\mathrm{O}_{2}$ consumption in control tubules. In cystine-loaded tubules, glycine increased basal and nystatin-stimulated $\mathrm{O}_{2}$ consumption in comparison to cystine-loaded tubules without glycine. Unlike hypoxic tubules, glycine did not significantly increase uncoupled tubule respiration (13). Although the mechanism is unknown, glycine is cytoprotective in these two types of proximal tubular injuries.

In summary, this study further characterized the defect in cystine-loaded proximal tubules. Consistent with our previous findings, the underlying defect is secondary to an alteration in cellular metabolism. This study demonstrates that the proximal tubule preferentially inhibits $\mathrm{O}_{2}$ consumption utilized for transport purposes, leaving nontransport-directed $\mathrm{O}_{2}$ consumption intact. Glycine is partially cytoprotective against the injury due to cellular cystine loading.

Acknowledgments. The authors thank Drs. Normal Siegel, Karen Gaudio, and Joel Weinberg for their helpful suggestions and Janell McQuinn for her able secretarial assistance.

\section{REFERENCES}

1. Gahl WA, Renlund M, Thoene JG 1989 Lysosomal transport disorders: cystinosis and sialic acid storage disorders. In: Scriver CR, Beaudet AL, Sly WS, Valle D (eds) The Metabolic Basis of Inherited Disease, 6th Ed McGraw-Hill, New York, pp 2619-2647

2. Schneider JA, Bradley K, Seegmiller JE 1967 Increased cystine in leukocytes from individuals homozygous and heterozygous for cystinosis. Science 157:1321-1322

3. Schneider JA, Rosenbloom FM, Bradley KH, Seegmiller JE 1967 Increased free-cystine content of fibroblasts cultured from patients with cystinosis. Biochem Biophys Res Commun 29:527-531

4. Patrick AD, Lake BD 1968 Cystinosis: electron microscopic evidence of lysosomal storage of cystine in lymph node. J Clin Pathol (Lond) 21:571575

5. Schulman JD, Bradley KH, Seegmiller JE 1969 Cystine: compartmentalization within lysosomes in cystinotic leukocytes. Science 166:1152-1154

6. Schulman JD, Bradley KH 1970 The metabolism of amino acids, peptides, and disulfides in lysosomes of fibroblasts cultured from normal individuals and those with cystinosis. J Exp Med 132:1090-1104

7. Goldman R, Kaplan A 1973 Rupture of rat liver lysosomes mediated by Lamino acid esters. Biochim Biophys Acta 318:205-216

8. Reeves JP 1979 Accumulation of amino acids of lysosomes incubated with amino acid methyl esters. J Biol Chem 254:8914-8921

9. Foreman JW, Bowring MA, Lee J, States B, Segal S 1987 Effect of cystine dimethyl ester on renal solute handling and isolated renal tubule transport in the rat: a new model of the Fanconi syndrome. Metabolism 36:11851191

10. Salmon RF, Baum M 1990 Intracellular cystine loading inhibits transport in the rabbit proximal convoluted tubule. J Clin Invest $85: 340-344$ 
11. Coor C Salmon RF, Quigley R, Marver D, Baum M 1991 Role of adenosine triphosphate (ATP) and NaK ATPase in the inhibition of proximal tubule transport with intracellular cystine loading. J Clin Invest 87:955-961

12. Weinberg JM, Humes HD 1986 Increases of cell ATP produced by exogenous adenine nucleotides in isolated rabbit kidney tubules. Am J Physiol 250:F720-F733

13. Weinberg JM, Davis JA, Abarzua M, Rajan $T 1987$ Cytoprotective effects of glycine and glutathione against hypoxic injury to renal tubules. J Clin Invest $80: 1446-1454$

14. Lowry OH, Rosebreough NJ, Farr AL, Randall RJ 1951 Protein measurement with the Folin phenol reagent. J Biol Chem 193:265-275
15. Weinberg JM, Davis JA, Abarzua M, Kiani T 1989 Relationship between cell adenosine triphosphate and glutathione content and protection by glycine against hypoxic proximal tubule cell injury. J Lab Clin Med 113:612-622

16. Gaudio KM, Thulin G, Ardito T, Kashgarian M, Siegel NJ 1989 Metabolic alterations in proximal tubule suspensions obtained from ischemic kidneys. Am J Physiol 257:F383-F389

17. Foreman JW, Benson L 1990 Effect of cystine loading and cystine dimethyl ester on renal brushborder membrane transport. Biosci Rep 10:455-459.

18. Mandel LJ, Takano T, Soltoff SP, Murdaugh S 1988 Mechanisms whereby exogenous adenine nucleotides improve rabbit renal proximal function during and after anoxia. J Clin Invest 81:1255-1264 